\title{
Impaired axonal transport of acetylcholinesterase in the sciatic nerve of alloxan-diabetic rats: effect of ganglioside treatment
}

\author{
P. Marini ${ }^{1}$, M. Vitadello ${ }^{1}$, R. Bianchi ${ }^{2}$, C. Triban $^{1}$ and A. Gorio ${ }^{1}$ \\ ${ }^{1}$ FIDIA Research Laboratories, Abano Terme, and ${ }^{2}$ Istituto di Ricerche Farmacologiche M. Negri, Milan, Italy
}

\begin{abstract}
Summary. The anterograde and retrograde axonal flow of acetylcholinesterase were studied in the sciatic nerve of alloxandiabetic rats after five weeks of experimental diabetes. A slight reduction of the anterograde axonal flow of the enzyme was found in alloxan-diabetic compared to control rats. Sedimentation analysis revealed a major reduction of anterograde axonal flow of the light globular forms of the enzyme $\left(\mathrm{G}_{1}+\mathrm{G}_{2}\right)$, which are probably conveyed by slow transport. There was also a minor reduction of the anterograde flow of the globular form $\mathrm{G}_{4}$, while no modification of the axonal flow of the heavy asymmetric form $A_{12}$ was found. Both $G_{4}$ and $A_{12}$ molecular forms are conveyed by fast axonal trans-
\end{abstract}

port. In contrast, no abnormality of the retrograde axonal flow of acetylcholinesterase was observed. Ganglioside treatment antagonized the decline of the anterograde axonal flow of the enzyme in alloxan-diabetic rats. These results are consistent with the view that experimental diabetic neuropathy is associated with axonal transport defects, and suggest a protective effect of ganglioside treatment against neuronal damage(s) related to the diabetic syndrome.

Key words: Axonal transport, acetylcholinesterase, experimental diabetic neuropathy, gangliosides.
Abnormalities of axonal transport have been implicated in the pathogenesis of experimental diabetic neuropathy $[1,2]$. Alterations of the slow axonal transport of radiolabelled proteins have been described in motor and sensory sciatic nerve axons of streptozotocin-diabetic rats [3-7]. As far as fast anterograde axonal transport is concerned, conflicting results have been obtained. Isotope labelling of protein has shown no change of fast axonal transport velocity in sensory axons of the sciatic nerve of streptozotocin-diabetic rats $[3,4,8,22]$. With the same technique, however, McLean and Meiri [9] found a reduced velocity of fast transported proteins in sciatic nerve motor axons of diabetic rats. A decreased orthograde accumulation of the transmitter-related enzyme acetylcholinesterase was also found in alloxandiabetic rats [10]. In a previous study of the anterograde axonal transport in the sciatic nerve of the mutant diabetic mouse $\mathrm{C} 57 \mathrm{BL} / \mathrm{Ks}(\mathrm{db} / \mathrm{db})$, we also described an alteration of the $\mathrm{G}_{1}-\mathrm{G}_{2}$ acetylcholinesterase molecular form axoplasmic flow [11] concomitant with the retardation of the slow axonal transport of identified cytoskeletal proteins [12]. The present study was undertaken to ascertain whether such a selective abnormality of the axonal transport of acetylcholinesterase was present in rats rendered diabetic by a single injection of alloxan. Alloxan has been used experimentally to induce diabe- tes ever since its toxic effects on B cells in the pancreatic islets were recognized [23]. Peripheral nerve electrophysiological abnormalities in alloxan-diabetic rats were first described by Eliasson [24]. Such nerve conduction changes were not observed in rats, which did not become diabetic after alloxan injection, indicating that these deficits were not due to a direct neurotoxic action of alloxan [24]. Subsequent reports showed that neurologic abnormalities induced by alloxan and streptozotocin could be obviated by insulin management [25-27].

We also tested the effects of ganglioside treatment on axonal transport abnormalities. Previous studies had shown that ganglioside treatment was effective in restoring electrophysiological and morphological parameters in genetic diabetic mice [13-16]. Interestingly, the restorative effects of gangliosides were observed at a stage of the disease characterized by the drop in acetylcholinesterase slow transport. Prior to this period ganglioside treatment was ineffective [14].

\section{Materials and methods}

Male albino COBS Sprague-Dawley rats (Charles Rivers) were used for this study. One group was given a single subcutaneous injection of $100 \mathrm{mg} / \mathrm{kg}$ alloxan (Sigma, St. Louis, MO, USA) in $100 \mathrm{mmol} / 1 \mathrm{ci}-$ trate-phosphate buffer ( $\mathrm{pH} 4.5$ ). After a week, glycosuria was deter- 
Table 1. Weight and glycaemia of control (saline- and gangliosidetreated) and diabetic (saline- and ganglioside-treated) rats at the time of killing

\begin{tabular}{lll}
\hline & Weight $(\mathrm{g} \pm \mathrm{SD})$ & $\begin{array}{l}\text { Glycaemia } \\
(\mathrm{mg} / \mathrm{dl} \pm \mathrm{SD})\end{array}$ \\
\hline $\begin{array}{l}\text { Control rats } \\
(n=25)\end{array}$ & $380 \pm 36$ & $100.6 \pm 12.8$ \\
$\begin{array}{l}\text { Ganglioside-treated } \\
\text { control rats } \\
(n=27)\end{array}$ & $382 \pm 44$ & $113.4 \pm 13.4$ \\
$\begin{array}{l}\text { Diabetic rats } \\
(n=25)\end{array}$ & $255 \pm 53$ & $425.4 \pm 186.5$ \\
$\begin{array}{l}\text { Ganglioside-treated } \\
\text { diabetic rats } \\
(n=26)\end{array}$ & $266 \pm 44$ & $350.8 \pm 72.4$ \\
\hline
\end{tabular}
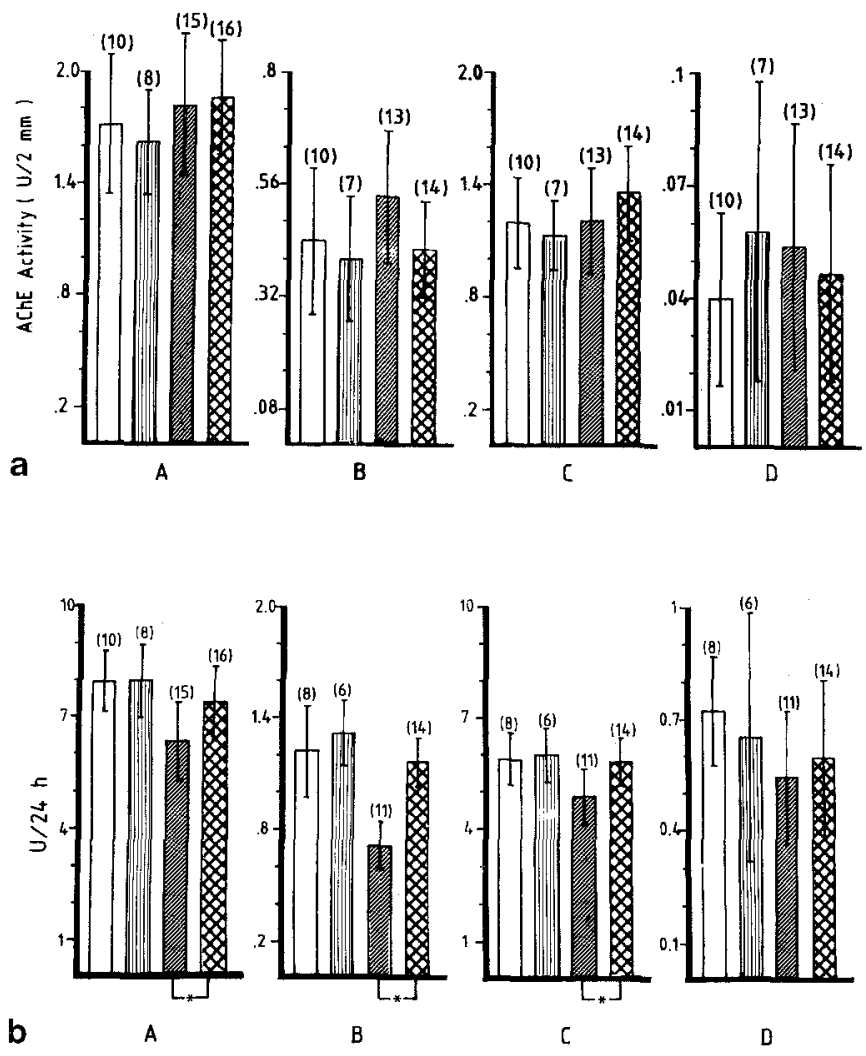

Fig. 1.a Basal AChE content in saline-treated control $\square$, gangliosidetreated control 䐬, saline-treated diabetic diabetic rats. No statistically significant difference was found both in total content (histogram A) and molecular form distribution $\left(\mathrm{G}_{1}+\mathrm{G}_{2}-\mathrm{B}, \mathrm{G}_{4}-\mathrm{C}\right.$ and $\left.\mathrm{A}_{12}-\mathrm{D}\right)$ between saline-treated and ganglioside-treated control and diabetic rats. b Total $\mathrm{AChE}$ anterograde accumulation (histogram $A$ ) and its molecular form distribution $\left(\mathrm{G}_{1}+\mathrm{G}_{2}-\mathrm{B}, \mathrm{G}_{4}-\mathrm{C}, \mathrm{A}_{12}-\mathrm{D}\right)$ in saline-treated control $\square$, gangliosidetreated control $⿴$, saline-treated diabetic and ganglioside-treated diabetic rख rats. Note that the accumulation of total, $\mathrm{G}_{1}+\mathrm{G}_{2}$ and $\mathrm{G}_{4}$ in ganglioside-treated diabetic rats is significantly increased compared to saline-treated diabetic rats, and very similar to the accumulation in the control rats treated with gangliosides or saline. Figures in brackets give the number of rats. Values are expressed as means $\pm S D$. $(*=p \leqslant 0.01)$ mined by Glucur-test strips (Boehringer, Mannheim, FRG). In addition, glycaemia was measured at the time of killing by the hexokinase method (Gluco-Quant, Boehringer, Mannheim, FRG). Alloxan-diabetic rats with glycaemic values below $250 \mathrm{mg} / \mathrm{dl}$ did not enter the study. A second group of age-matched rats were the untreated controls.

\section{Determinations of AChE flow}

The AChE anterograde and retrograde axonal flow were determined by the test-section method described by Couraud and Di Giamberardino [17]. Briefly, under ether anaesthesia the left sciatic nerves of rats were cut at the mid-femur level and a $2 \mathrm{~mm}$ nerve segment was resected to determine the basal level of AChE. Twenty-four hours later the 2-mm extremity of the proximal and distal stumps, where AChE accumulation was strictly confined, were excised and assayed for $\mathrm{AChE}$ content and concentration of molecular forms. Nerve segments were homogenized in $300 \mu \mathrm{l}$ of extraction buffer $(1 \mathrm{~mol} / 1 \mathrm{NaCl}$, $100 \mathrm{mmol} / \mathrm{l}$ phosphate buffer, $\mathrm{pH} 7.0,1 \%$ Triton X-100; and $1.9 \mathrm{mg} /$ $\mathrm{ml} \mathrm{EGTA}, 1 \mathrm{mg} / \mathrm{ml}$ bacitracin and $0.16 \mathrm{mg} / \mathrm{ml}$ benzamidine as protease inhibitors). The homogenates were centrifuged $20 \mathrm{~min}$ at $20,000 \mathrm{~g}$ and $4{ }^{\circ} \mathrm{C}$, and usually $20 \mu \mathrm{l}$ supernatant was assayed for AChE activity by a slight modification of the Ellman's method [17, 28] using $0.75 \mathrm{mmol} / 1$ acetylthiocholine as substrate and $0.1 \mathrm{mmol} / 1$ Tetraisoprophylpyrophosphoramide (ISO-OMPA, Sigma, St. Louis, MO, USA) as non-specific cholinesterase inhibitor (one unit AChE represents the quantity of enzyme hydrolyzing $1 \mathrm{nmol} \mathrm{AcThCh} / \mathrm{min}$ ). The Ellman's buffer, supplemented with $0.1 \mathrm{mmol} / 1$ ISO-OMPA and $0.75 \mathrm{mmol} / \mathrm{l}$ acetylthiocholine, was utilized to measure acetylthiocholine spontaneous hydrolysis to correct the enzymatic activity measured in sciatic nerve samples. The remainder of the supernatant was layered on a 5-20\% linear concentration gradient of sucrose in extraction buffer and centrifuged $19 \mathrm{~h}$ at $250,000 \mathrm{~g}$ and $4^{\circ} \mathrm{C}$ in a SW 41 Beckman rotor (Beckman Instruments, Palo Alto, CA, USA). The gradients were then divided into 60-70 fractions and assayed for $\mathrm{AChE}$ activity. The amount of each AChE form was determined from its relative proportion in the sedimentation profile. The accumulation of $\mathrm{AChE}$ was calculated on the extremity of the proximal and distal stumps, corrected for the enzymatic concentration present within the intact nerve.

\section{Treatment of diabetic and control rats}

Alloxan-diabetic and control rats were randomly subdivided into two groups respectively. The first group, comprising alloxan-diabetic and control rats, received daily intraperitoneal injections of $10 \mathrm{mg} / \mathrm{kg}$ of a bovine brain ganglioside mixture $\left(\mathrm{GM}_{1} 21 \%, \mathrm{GD}_{1 \mathrm{a}} 39.7 \%, \mathrm{GD}_{\mathrm{bb}} 16 \%\right.$ and $\mathrm{GT}_{\mathrm{fb}} 19 \%$ ) for 4 weeks, starting 1 week after the induction of diabetes. The second group of diabetic and control rats received daily intraperitoneal injections of saline.

\section{Statistical analysis}

Statistical analysis were performed utilizing the unpaired Student's ttest.

\section{Results}

\section{Changes in body weight}

Seven-week-old rats entered the study at a starting weight between $175-200 \mathrm{~g}$. Five weeks later, at the time of killing, control rats showed a significant increase in body weight. In contrast, the growth rate of alloxan-diabetic rats was impaired. Serum glucose was raised sub- 


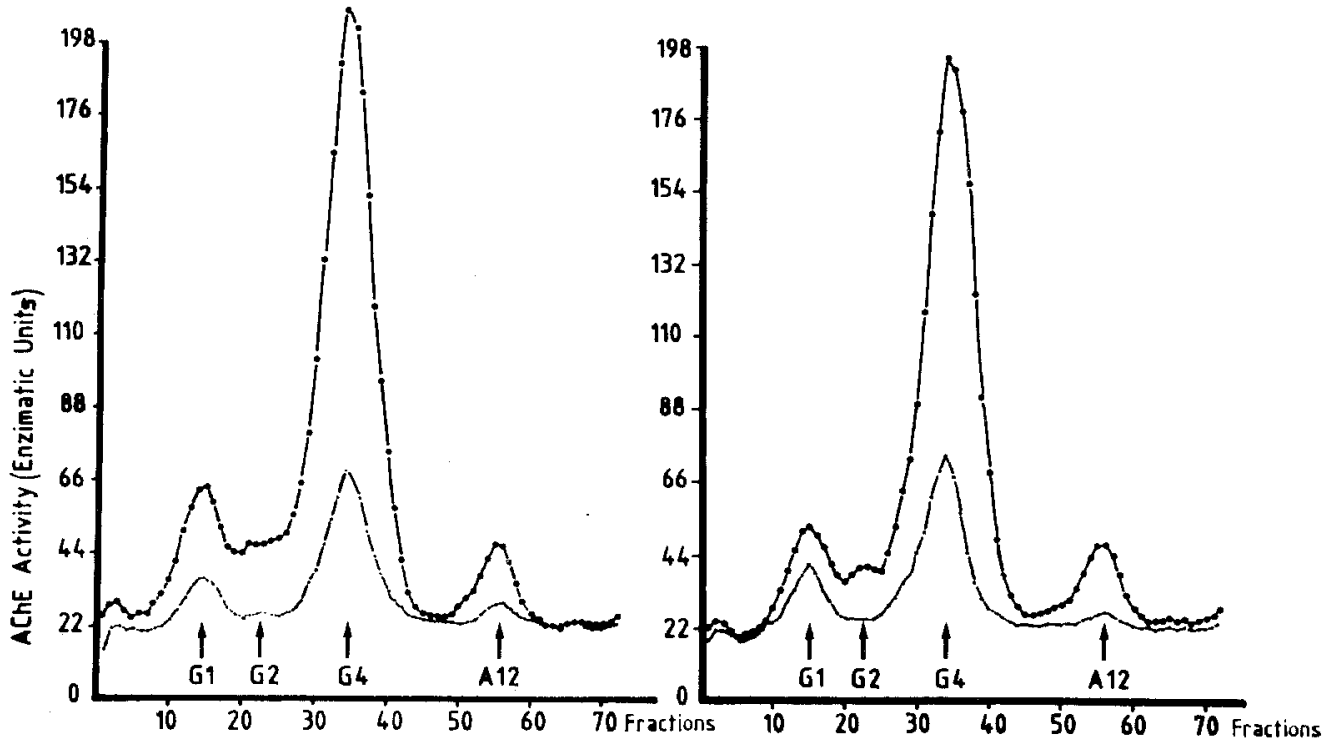

Fig. 2. Sedimentation profile of $\mathrm{AChE}$ in intact sciatic nerve (lower profiles) and in the $2 \mathrm{~mm}$ nerve segments proximal to a test section of a control (left) and a diabetic (right) rat. Four molecular forms of AChE were separated. Their sedimentation coefficients were respectively $4 \mathrm{~S}$ $\left(\mathrm{G}_{1}\right), 6 \mathrm{~S}\left(\mathrm{G}_{2}\right), 10 \mathrm{~S}\left(\mathrm{G}_{4}\right)$, and $16 \mathrm{~S}$ $\left(\mathrm{A}_{12}\right)$. A reduced accumulation of $\mathrm{G}_{1}$ and $\mathrm{G}_{2}$, and, to a minor degree, of $\mathrm{G}_{4}$ can be noted in the diabetic sciatic nerve compared to control

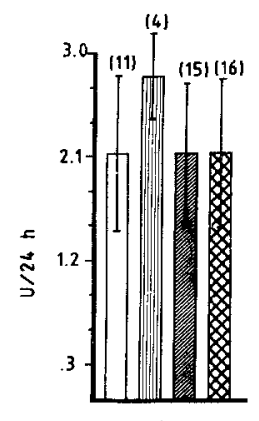

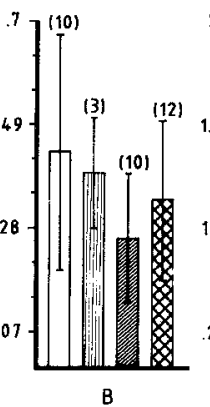

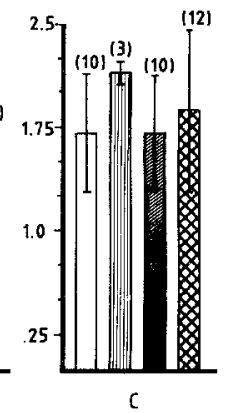

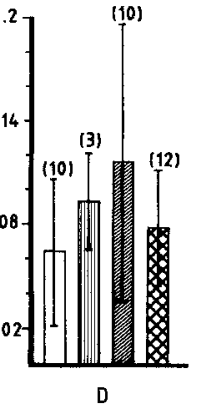

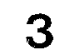

Fig. 3. Total AChE retrograde accumulation (histogram $A$ ) and its molecular form distribution $\left(G_{1}+G_{2}-B, G_{4}-C, A_{12}-D\right)$ in saline-treated control $\square$, ganglioside-treated control [ill, saline-treated diabetic $\mathbb{N}$, and ganglioside-treated diabetic rats. No statistically significant difference among the four groups was measured. Figures in brackets give the number of experiments. Values are expressed as means $\pm \mathrm{SD}$

stantially in all alloxan-treated rats as compared to controls. Ganglioside treatment did not modify these parameters in both groups (Table 1).

\section{Axonal transport of acetylcholinesterase}

After 5 weeks of uncontrolled diabetes, the total amount of AChE activity per unit length of sciatic nerve of diabetic rats was not different than controls (Fig. 1 a). In addition, the sedimentation pattern revealed no alteration in the distribution of the enzymatic activity between the AChE different molecular forms (Fig. $1 \mathrm{a}$ and 2).

The anterograde accumulation at a test section showed a $20 \%$ reduction in diabetic compared to control rats (Fig. 1b). However, the calculation of the relative contribution of the different molecular forms to the total accumulation revealed a dramatic deficit of $\mathrm{G}_{1}$ and $\mathrm{G}_{2}$ molecular form accumulation in diabetic compared to control rats (Fig. $1 \mathrm{~b}$ and 2). A minor reduction was also observed for $G_{4}$ and $A_{12}$ AChE molecular forms. Differences were statistically significant $(p<$ 0.01 ) only for total, $G_{1}+G_{2}$ and for $G_{4}$ (see Figs. $1 b$ and 2).

In contrast, no significant quantitative and qualitative reduction of the retrograde axonal flow of the enzyme was measured in alloxan-diabetic rats (Fig.3).

Ganglioside treatment modified neither total AChE enzymatic activity in intact sciatic nerves of both diabetic and control rats, nor its distribution between different molecular forms (Fig. 1 a). The anterograde axonal flow of the enzyme in ganglioside-treated diabetic rats was comparable to control (Fig. 1b). In particular, we did not observe a noticeable deficit of accumulation of $\mathrm{G}_{1}-\mathrm{G}_{2}$ molecular forms occurring in alloxan-diabetic rats treated with saline. The minor modification of anterograde axonal flow of $\mathrm{G}_{4}$ was no more observable in ganglioside-treated rats. The effect of ganglioside treatment could not be ascribed to the enhancement of AChE enzymatic activity, since the same amount of enzyme accumulated at a test section of both gangliosideand saline-treated control rats (Fig. 1b).

\section{Discussion}

Our investigation was centered on the effects of ganglioside treatment upon the neurological complications developed in alloxan-diabetic rats. The impairment of the orthograde axonal transport of $\mathrm{AChE}$ is a characteristic neuronal deficit in experimental diabetes. A reduction of anterograde axonal flow of AChE was first described by Schmidt et al. [10]; it was found that, 3-4 weeks after streptozotocin injection, the accumula- 
tion of the enzyme proximal to a sciatic nerve constriction was reduced by $20 \%$. A similar study on the genetically diabetic mouse $\mathrm{C} 57 \mathrm{BL} / \mathrm{Ks}(\mathrm{db} / \mathrm{db})$ revealed that such an impairment was due to the selective flow reduction of $G_{1}-G_{2} A C h E$ molecular forms [15]. Our results point to a major impairment of $G_{1}-G_{2}$ anterograde axonal flow in alloxan-induced diabetic neuropathy. Since $G_{1}$ and $G_{2}$ AChE molecular forms are probably conveyed by slow axonal transport [16], the present results further support the relevance of slow transport impairment in the pathogenesis of experimental diabetic neuropathy $[3-7,8-12,29]$.

On the other hand, the relationship between diabetic neuropathy and fast axonal transport defects is more complex. The $\mathrm{G}_{4}$ and $\mathrm{A}_{12}$ forms of acetylcholinesterase are conveyed by fast axonal transport [17]. We found a minor, but statistically significant, reduction of the $G_{4}$ $\mathrm{AChE}$ molecular form axonal flow, while no statistically significant alteration of $A_{12}$ flow was found. Such a deficit of $G_{4}$ axonal flow was not observed in the genetically diabetic mouse throughout its lifetime [11]. The genetic mouse develops a gradual, progressive neuropathy over several months [11], while alloxan and streptozotocin cause neurological alterations within a few days after intoxication [3]. However, Swiss albino mice poisoned with alloxan develop transport deficits identical to rats, i.e. the axonal flow of $\mathrm{G}_{1}-\mathrm{G}_{2}$ and $\mathrm{G}_{4}$ $\mathrm{AChE}$ molecular forms is reduced in a similar way (Vitadello et al., unpublished observations). These facts suggest that $\mathrm{G}_{4}$ flow impairment may not be speciesrelated, but rather be dependent upon the mode of onset of the diabetic syndrome.

The observed reduction of anterograde axonal flow of $\mathrm{AChE}$ can be attributed either to a reduced transport velocity or to a reduced clearance (quantity of transported enzyme per unit length of nerve). At present we cannot decide between these two hypotheses, although several reports showing an impairment of transport velocity might favor the former one [3-7, 12, 29].

Ganglioside treatment prevented the onset of AChE axonal transport deficits, confirming previously reported positive effects of ganglioside treatment on electrophysiological and morphometric parameters in genetic and alloxan-diabetic animals [13-16]. In particular, the beneficial effects of ganglioside treatment in the genetically diabetic mouse C57 BL/Ks $(\mathrm{db} / \mathrm{db})$ were shown only in 180-day-old diabetic mice $[13,14,16]$, i.e. at a time when the axonal flow of $G_{1}$ and $G_{2} A C h E$ molecular forms was altered [11]. Ganglioside effects were not due to an enhancement of AChE enzymatic activity because: (a) basal AChE activity level and molecular form distribution were not modified by ganglioside treatment in both diabetic and control rats; (b) no modification of $\mathrm{AChE}$ accumulation was observed in ganglioside-treated control rats. However, it is possible that the positive effect of ganglioside treatment was due to the stabilization of the clearance of the enzyme, if it was reduced in diabetic animals.
Gangliosides, $\mathrm{GM}_{1}$ in particular, have a regrowth stimulating effect and/or a protective effect against neurotoxin induced retrograde degeneration [18]. It has been previously reported that ganglioside treatment of diabetic neuropathy in C57 $\mathrm{BL} / \mathrm{Ks}(\mathrm{db} / \mathrm{db})$ mice promoted a significant improvement of nerve conduction velocity and a normalization of axonal size [14]. It has been suggested that alterations of axonal morphology and axonal transport are correlated in experimental diabetic neuropathy [29]. Therefore, the improvement of axonal size might depend on the improvement of axonal flow after ganglioside treatment. The molecular mechanisms by which gangliosides act are still unclear, although some experimental conditions have suggested that these molecules may have a decay-preventing activity on neuronal functions. Sodium loading and hypoxia experiments performed with ex vivo neuromuscular preparations showed that gangliosides increased the resistance to ionic disbalances and low oxygen level [19-21]. It is conceivable that the same basic mechanisms are responsible for the prevention of $\mathrm{AChE}$ transport deficits occurring in experimental diabetic neuropathy.

Acknowledgements. Authors wish to thank Mr. M. Fabris for his skillful technical assistance.

\section{References}

1. Sidenius $P(1982)$ The axonopathy of diabetic neuropathy. Diabetes 31: 689-693

2. Tomlinson DR, Mayer JH (1984) Defect of axonal transport in diabetes mellitus a possible contribution to the etiology of diabetic neuropathy. J Auton Pharmacol 4: 59-72

3. Sidenius P, Jakobsen J (1979) Axonal transport in early experimental diabetes. Brain Res 173: 315-330

4. Jakobsen J, Sidenius P (1980) Decreased axonal transport of structural proteins in streptozotocin diabetic rat. J Clin Invest 66 : 292-297

5. McLean WG, Meiri KF (1980) Slow axonal transport in rat sciatic motor nerves during early experimental diabetes. J Physiol (London) 310:57 P

6. Takenaka T, Inomata K, Harie H (1982) Slow axoplasmic flow of labeled proteins in sciatic nerves of streptozotocin diabetic rats and methylcobalamin treated rats. In: Goto Y, Horiuchi A, Kogure K (eds) Diabetic neuropathy. Excerpta Medica, Amsterdam, pp 99-103

7. Mayer JH, Tomlinson DR, McLean WG (1984) Slow orthograde axonal transport of radiolabeled protein in sciatic motorneurons of rats with short-term experimental diabetes: effect of treatment with an aldose reductase inhibitor or myo-inositol. J Neurochem 43: $1265-1270$

8. Bisby MA (1980) Axonal transport of labeled protein and regeneration rate in nerve of streptozotocin-diabetic rats. Exp Neurol 69: $74-84$

9. Meiri KF, McLean WG (1982) Axonal transport of protein in motor fibres of experimentally diabetic rats-Fast anterograde transport. Brain Res 238: 77-88

10. Schmidt RE, Matschinsky FM, Godfrey DA, Williams AD, McDougal Jr DB (1975) Fast and slow axoplasmic flow in sciatic nerve of diabetic rats. Diabetes 24: 1081-1085

11. Vitadello M, Couraud JY, Hassig R, Gorio A, Di Giamberardino L (1983) Axonal transport of acetylcholinesterase in the diabetic mutant mouse. Exp Neurol 82: 143-147 
12. Vitadello M, Filliatreau G, Dupont JL, Hassig R, Gorio A, Di Giamberardino L (1985) Altered axonal transport of cytoskeletal proteins in the mutant diabetic mouse. J Neurochem 45: 860-868

13. Norido F, Canella P, Gorio A (1982) Ganglioside treatment of neuropathy in diabetic mice. Muscle Nerve 5: 107-110

14. Norido F, Canella R, Zanoni R, Gorio A (1984) The development of diabetic neuropathy in the $\mathrm{C} 57 \mathrm{BL} / \mathrm{Ks}(\mathrm{db} / \mathrm{db})$ mouse and its treatment with gangliosides. Exp Neurol $83: 221-233$

15. Gorio A, Aporti F, Di Gregorio F, Schiavinato A, Siliprandi R, Vitadello $M$ (1984) Ganglioside treatment of genetic and alloxan-induced diabetic neuropathy. In: Ledeen RW, Yu RK, Rapport MM, Suzuki K (eds) Ganglioside structure, function and biomedical potential. Plenum New York London, pp 549-564

16. Schiavinato A, Morandin A, Gorio A (1985) Quantitative analysis of myelin and axolemma particle distribution in C57 BL/KS diabetic mice and effects of ganglioside treatment. J Neurol Sci 69: 301-317

17. Couraud JY, Di Giamberardino L (1980) Axonal transport of the molecular forms of acetylcholinesterase in chick sciatic nerve. $J$ Neurochem 35: 1035-1066

18. Jonsson $G$, Gorio A, Hallman $H$, Janigro D, Kojima $H$, Luthman J, Zanoni R (1984) Effects of $\mathrm{GM}_{1}$ ganglioside on developing and mature serotonin and noradrenaline neurons lesioned by selective neurotoxins. J Neurosc Res 12: 459-476

19. Janigro D, Di Gregorio F, Vyskocil F, Gorio A (1984) Gangliosides' dual mode of action: a working hypothesis. J Neurosc Res 12: 499-509

20. Bianchi R, Janigro D, Milan F, Giudici G, Gorio A "In vivo" treatment with $\mathrm{GM}_{1}$ prevents the rapid decay of ATPase activities and mitochondrial damage in hippocampal slices. Brain Res 364: 400-404

21. Vyskocil F, Di Gregorio F, Gorio A (1985) The facilitating effect of gangliosides on the electrogenic $\left(\mathrm{Na}^{+} / \mathrm{K}^{+}\right)$pump and on the resistance of the membrane potential to hypoxic in neuromuscular preparations. Pflügers Arch 403:1-6

22. Whiteley SJ, Townsend J, Tomlinson DR, Brown AM (1985) Fast orthograde axonal transport in sciatic motoneurones and nerve temperature in streptozotocin-diabetic rats. Diabetologia 28: 847-851

23. Dunn JS, Sheehan HL, McLechtie NG (1943) Necrosis of the islets of Langherans produced experimentally. Lancet 1: 484-487

24. Eliasson SG (1964) Nerve conduction changes in experimental diabetes. J Clin Invest 43: 2353-2358

25. Mayer JH, Tomlinson DR (1983) Axonal transport of cholinergic transmitter enzymes in vagus and sciatic nerves of rats with acute experimental diabetes mellitus; correlation with motor nerve conduction velocity and effects of insulin. Neuroscience 9: 951-957

26. Sidenius P, Jakobsen J (1982) Reversibility and preventability of the decrease in slow transport velocity in experimental diabetes. Diabetes 31: 689-693

27. Jakobsen J, Brimijoin S, Skau K, Sidenius P, Wells D (1981) Retrograde axonal transport of transmitter enzymes, fucose labeled protein and nerve growth factor in streptozotocin diabetic rats. Diabetes 30: 797-803

28. Ellman GL, Courtney KD, Andres V, Featherstone RM (1961) A new rapid colorimetric determination of acetylcholinesterase activity. Biochem Pharmacol 7:89-95

29. Medori R, Autilio-Gambetti L, Monaco S, Gambetti P (1985) Experimental diabetic neuropathy impairment of slow transport with changes in axon cross-sectional area. Proc Natl Acad Sci USA $82: 7716-7720$

Received: 24 October 1985

and in revised form: 3 February 1986

Dr. Maurizio Vitadello

Fidia Neurobiological Research Laboratories

Via Ponte della Fabbrica 3/A

I-35031 Abano Terme (PD)

Italy 